\title{
Gas Bubble Growth In Muddy Sediments
}

\author{
Bruce D. Johnson \\ Department of Oceanography, Dalhousie University \\ Halifax, Nova Scotia, Canada B3H 4J1 \\ phone: (902) 494-2089 fax: (902) 494-3877 email: bjohnson@is.dal.ca \\ Bernard P. Boudreau \\ Department of Oceanography, Dalhousie University \\ Halifax, Nova Scotia, Canada B3H 4J1 \\ phone: (902) 494-8895 fax: (902) 494-3877 email: bpboudre@is.dal.ca
}

Award Number: N00014-99-1-0063

\section{LONG-TERM GOALS}

Our long term goal is a quantitative, mechanistic and predictive understanding of the dynamics of bubbles and bubble populations in marine sediments. We believe that this information can be used to improve and test acoustic backscatter models for sediments and to better understand the ebullitive flux of methane, an important "greenhouse gas", to the atmosphere.

\section{OBJECTIVES}

The immediate objective is to develop a working model for the growth of a single, isolated bubble in a marine sediment. This modeling is being guided by data describing bubble growth behavior obtained in laboratory studies.

\begin{abstract}
APPROACH
We have a strategy of coordinated laboratory and modeling research to achieve our objective. The laboratory work (directed by Bruce Johnson and assisted by Bruce Gardiner and Regine Maass) is focused on developing an understanding of the growth behavior of bubbles in sediments through determining the relationship between stress and strain during bubble expansion. The modeling research (Bernard Boudreau and Bruce Gardiner), guided by the laboratory results, is directed toward developing appropriate model(s) for observed bubble growth characteristics.
\end{abstract}

\section{WORK COMPLETED}

During the third (final) year of this granting period, we have made substantial progress in achieving our objective. We have characterized the mode of growth of bubbles in samples of marine sediment as growth by fracture and have determined values of the important variables, including the critical stress intensity factor, $\mathrm{K}_{1 \mathrm{c}}$, and Young's modulus. These results have been described in a paper submitted to the Journal of Marine Geology. A diffusion-reaction model that incorporates the experimental results for the mechanical response of sediments to bubble growth has been developed in which a distributed source of methane drives bubble growth by fracture. This work has been 


\section{Report Documentation Page}

Form Approved

OMB No. 0704-0188

Public reporting burden for the collection of information is estimated to average 1 hour per response, including the time for reviewing instructions, searching existing data sources, gathering and maintaining the data needed, and completing and reviewing the collection of information. Send comments regarding this burden estimate or any other aspect of this collection of information,

including suggestions for reducing this burden, to Washington Headquarters Services, Directorate for Information Operations and Reports, 1215 Jefferson Davis Highway, Suite 1204, Arlington

VA 22202-4302. Respondents should be aware that notwithstanding any other provision of law, no person shall be subject to a penalty for failing to comply with a collection of information if it

does not display a currently valid OMB control number.

\begin{tabular}{|c|c|c|}
\hline $\begin{array}{l}\text { 1. REPORT DATE } \\
\text { 30 SEP } 2002\end{array}$ & 2. REPORT TYPE & $\begin{array}{l}\text { 3. DATES COVERED } \\
\mathbf{0 0 - 0 0 - 2 0 0 2} \text { to 00-00-2002 }\end{array}$ \\
\hline \multirow{3}{*}{\multicolumn{2}{|c|}{$\begin{array}{l}\text { 4. TITLE AND SUBTITLE } \\
\text { Gas Bubble Growth In Muddy Sediments }\end{array}$}} & 5a. CONTRACT NUMBER \\
\hline & & 5b. GRANT NUMBER \\
\hline & & 5c. PROGRAM ELEMENT NUMBER \\
\hline \multirow{3}{*}{\multicolumn{2}{|c|}{ 6. AUTHOR(S) }} & 5d. PROJECT NUMBER \\
\hline & & 5e. TASK NUMBER \\
\hline & & 5f. WORK UNIT NUMBER \\
\hline \multicolumn{2}{|c|}{$\begin{array}{l}\text { 7. PERFORMING ORGANIZATION NAME(S) AND ADDRESS(ES) } \\
\text { Department of Oceanography, Dalhousie University,,Halifax, Nova } \\
\text { Scotia, Canada B3H 4J1, , }\end{array}$} & $\begin{array}{l}\text { 8. PERFORMING ORGANIZATION } \\
\text { REPORT NUMBER }\end{array}$ \\
\hline \multirow{2}{*}{\multicolumn{2}{|c|}{ 9. SPONSORING/MONITORING AGENCY NAME(S) AND ADDRESS(ES) }} & 10. SPONSOR/MONITOR'S ACRONYM(S) \\
\hline & & $\begin{array}{l}\text { 11. SPONSOR/MONITOR'S REPORT } \\
\text { NUMBER(S) }\end{array}$ \\
\hline
\end{tabular}

12. DISTRIBUTION/AVAILABILITY STATEMENT

Approved for public release; distribution unlimited

13. SUPPLEMENTARY NOTES

14. ABSTRACT

Our long term goal is a quantitative, mechanistic and predictive understanding of the dynamics of bubbles and bubble populations in marine sediments. We believe that this information can be used to improve and test acoustic backscatter models for sediments and to better understand the ebullitive flux of methane, an important ???greenhouse gas???, to the atmosphere.

15. SUBJECT TERMS

16. SECURITY CLASSIFICATION OF:

\begin{tabular}{c|c|c|c|c|c}
$\begin{array}{c}\text { a. REPORT } \\
\text { unclassified }\end{array}$ & $\begin{array}{c}\text { b. ABSTRACT } \\
\text { unclassified }\end{array}$ & $\begin{array}{c}\text { ABSTRACT } \\
\text { unclassified }\end{array}$ & $\begin{array}{c}\text { Same as } \\
\text { Report (SAR) }\end{array}$ & $\mathbf{5}$ & RESPONSIBLE PERSON \\
& & &
\end{tabular}


described in two papers, one submitted to Geochimica et Cosmochimica Acta and the other to the International Journal of Heat and Mass Transfer.

More recently, we have taken another step toward achieving our long term goals by conducting experiments into the dynamics of bubble rise in sediments. We have developed the methods and the apparatus, and are presently collecting data on rise rates as a function of bubble size and the properties of natural and surrogate sediments.

\section{RESULTS}

A. Experimental Work. Through X-ray images, stress-strain results and observations with surrogate materials we have demonstrated that the principal mechanism of bubble growth in our sediment samples is by fracture. This growth mechanism also explains coin or disk-shaped bubbles that have been reported in X-ray tomography images in other natural sediments (Abegg et al., 1994). We have shown that experimental results for stress and strain that we obtained for bubble growth in natural sediment samples are consistent with the principles of linear elastic fracture mechanics (LEFM), and we have used these experimental results to determine the critical stress intensity factor, $\mathrm{K}_{1 \mathrm{c}}$, which is the principal material property that determines fracture behavior. Values of $\mathrm{K}_{1 \mathrm{c}}$ for our sediment samples (Cow Bay, Nova Scotia) range from about $2.3 \times 10^{-4} \mathrm{M} \mathrm{N} \mathrm{m}^{-3 / 2}$ to about $4.1 \mathrm{X}^{-4} \mathrm{M} \mathrm{N} \mathrm{m}^{-3 / 2}$. In addition, we have estimated the critical stress intensity factor for Eckernförd Bay samples by determining the eccentricity of bubbles in published images (Abegg, et al., 1994). The $\mathrm{K}_{1 \mathrm{c}}$ obtained in this way is similar to our Cow Bay results and is about $5.5 \times 10^{-4} \mathrm{M} \mathrm{N} \mathrm{m}^{-3 / 2}$. The manuscript describing this work has been submitted to the Journal of Marine Geology.
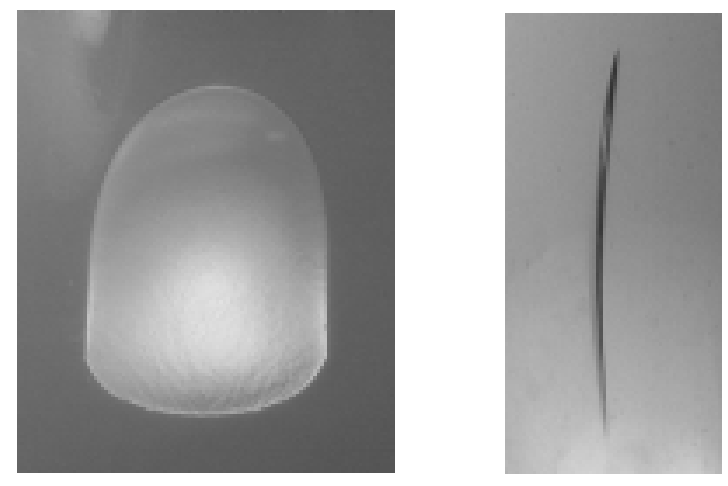

Figure 1: Bubble rising by buoyancy driven fracture. Left image is front view showing bubble $5 \mathrm{~cm}$ long by $3 \mathrm{~cm}$ wide. Right image is side view showing bubble thickness of about $1 \mathrm{~mm}$.

In studies of bubble rise in natural and surrogate sediment materials, we have determined that the mechanism of rise is by buoyancy-driven fracture. Bubbles rising in this manner typically acquire a shape that is round on the leading edge, more square on the trailing edge and have a thickness of 1 to $2 \mathrm{~mm}$. We are now conducting experiments to determine rise speed as a function of parameters such as $\mathrm{K}_{1 \mathrm{c}}$, E, and $\Delta \rho$. We then plan to use these data to develop a model of rise by fracture in a range of sediment types. 
B. Theory/Modeling. We have used the experimental results described above to guide development of models of bubble growth by fracture with methane supplied from a distributed source. Two models have been developed for oblate spheroidal bubbles: one model with constant bubble eccentricity (DLCE, i.e., diffusion limited constant eccentricity) and the other with eccentricity varying according to linear elastic fracture mechanics (LEFM). The predictions of each of these models have been compared to the predicted rate of growth for a spherical bubble. Both the DLCE and LEFM results show that oblate spheroidal bubbles grow substantially faster than spherical bubbles under the same conditions (figure 2) and can reach sizes observed in marine sediments in tens of days. In additon, the LEFM model results show many of the features of the pressure-volume curve obtained for injection of gas into natural sediment samples, e.g., the sawtooth pattern of pressure rise and fall as gas is injected.

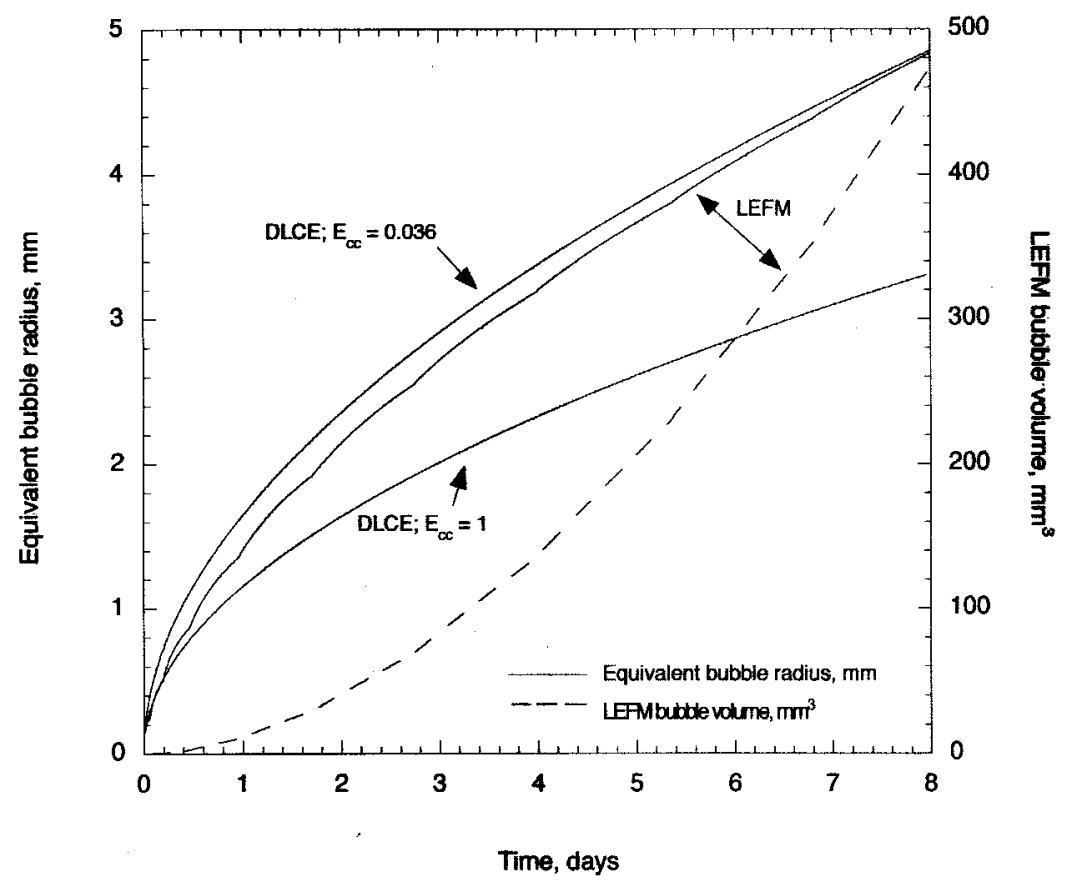

Figure 2: Graph showing model results for bubble growth rates predicted for: oblate spheroidal bubble of constant eccentricity (DLCE; eccentricity of 0.036); spherical bubble (DLCE; eccentricity of 1 ) and oblate spheroidal bubble with eccentricity determined by the principles of linear elastic fracture mechanics (LEFM).

[Both oblate spheroidal bubbles grow substantially faster than the spherical bubble; the LEFM bubble grows more slowly than the constant eccentricity bubble to about $5 \mathrm{~mm}$ equivalent radius and faster at larger sizes.]

In the LEFM treatment, bubbles at small sizes grow relatively more slowly than predicted by DLCE, but at larger sizes grow faster. One particularly interesting prediction of the LEFM model, and a consequence of bubble growth in an elastic medium, is that small bubbles may stop growing when the bubble pressure required for fracture exceeds the gas pressure in the pore water. Under such 
conditions, larger bubbles grow at the expense of smaller bubbles. The manuscript describing this work has been submitted to Geochimica Cosmochimica Acta, and a more general treatment submitted to the International Journal of Heat and Mass Transfer.

\section{IMPACT/APPLICATIONS}

Bubbles in sediments can seriously compromise acoustic sensing of naval mines, destabilize structures that rest on the bottom, and transport methane, a potent greenhouse gas, to the atmosphere. Thus, understanding bubble formation (and movement) in sediments constitutes an important practical and scientific problem. Our findings will provide information that could help remove/filter bubbleproduced acoustic interference, predict mechanical stability of sediments, and place limits on estimates of the flux of methane to the atmosphere.

\section{TRANSITIONS}

We are not formally cooperating with any particular ONR funded project, but we hope to integrate our study with work being done in the Bubble-Acoustics DRI in the future.

\section{REFERENCES}

Abegg, F., A. Anderson, L. Buzi, A.P. Lyons and T.H. Orsi 1994. Free methane concentration and bubble characteristics in Eckernförd Bay, Germany in: Forschungsanstalt der Bundeswehr für Wasserschall- und Geophysik (FWG); T.F. Wever, Editor., 84-89.

\section{PUBLICATIONS}

Gardiner, B.S., B.P. Boudreau and B.D. Johnson. Growth of disk shaped bubbles in sediments by fracture; submitted to Geochim. Cosmochim. Acta. August 2001.

Gardiner, B.S., B.P. Boudreau and B.D. Johnson. Diffusion-limited growth of a disc-shaped bubble; submitted to the International Journal of Heat and Mass Transfer. August 2001.

Johnson, B.D., B.P. Boudreau, B.S. Gardiner and R. Maass. Mechanical Response of Sediments to Bubble Growth; submitted to J. Mar. Geol.; Jan. 2001.

Boudreau, B.P., B.S. Gardiner and B.D. Johnson 2001. Erratum: Rate of growth of isolated bubbles in sediments with a distributed source of methane; Limnol. Oceanogr., June 2001. in press.

Boudreau, B.P., B.S. Gardiner and B.D. Johnson 2001. Rate of growth of isolated bubbles in sediments with a distributed source of methane; Limnol. Oceanogr., 46, 616-622. 